\title{
Phytochemical estimation of germinated Trigonella foenum-graecum L. seed extract for better application in phytotherapy
}

\author{
Sahar Idris, Anuradha Mishra and Mohammad Khushtar \\ Faculty of Pharmacy, Integral University, Lucknow-226026, Uttar Pradesh, India
}

\begin{tabular}{l} 
Article Info \\
\hline Article history \\
Received 3 September 2021 \\
Revised 27 October 2021 \\
Accepted 29 October 2021 \\
Published Online 30 December 2021
\end{tabular}

Keywords

Trigonella foenum graecum

Phytoconstituents

Powdermicroscopy

Physico-chemical evaluations LCMS

\begin{abstract}
Fenugreek (Trigonella foenum-graecum L.), popularly known as methi, is a Leguminosae plant with many pharmacological and pharmaceutical benefits. Traditionally, it is used in Ayurveda, Chinese and Arabic systems of medicine. Fenugreek leaves, seeds, and oil has the potential to cure a variety of malady or illness such as gastric ulcer, gout, epilepsy, piles, chronic cough, bronchitis, and arthritis. Some research findings suggest that fenugreek seeds possess antioxidant, anti-inflammatory, antipyretic, antitumor, antimicrobial, and antidiabetic activity. Fenugreek seeds contain various essential phytoconstituents which are responsible for the pharmacological effects. The goal of this study is to explain the preliminary phytochemical standard of fenugreek seeds with powder microscopy and LCMS analysis.
\end{abstract}

\section{Introduction}

Herbal plants are nearly universally used to cure a variety of ailments, and their use has grown in popularity around the world. Herbal medicines are increasingly being used by the general public to avoid contemporary therapeutic drugs on their own volition (Al-Jenoobi et al., 2014). Still in developing countries, around 80 per cent public utilizes conventional medications for their health care, which is generally based on plants and animals (Thakur et al., 2018). Herbs are the natural antioxidant which neutralizes the free radicals and essential for human health (Malik et al., 2020). The plant extracts or their active principles are used in the majority of traditional therapies to cure various diseases (Mathe, 2018). Vegetative medication is increased due to minimum toxicity or side effect, less expensive and more important, easy availability in comparison to allopathic drugs (Parihar et al., 2014; Tiwari et al., 2016). Herbal drugs are used because of their: (i) habitually they are the only option obtainable; (ii) research based validation regarding the occurrence of therapeutically vigorous phytoconsti-tuents; (iii) they have relatively very few detrimental side effects and, hence can be taken directly as folk medicine (Sharma, 2021). India is very affluent country in-plant medical traditions and about five hundred plants with their therapeutic uses are mentioned in pristine articles and around eight hundred plants have been utilized in different medicine system (Verma and Singh, 2008). World Health Organization (WHO) established some specific recommendations for assessing the safety, efficacy, and quality of herbal medicines. Herbs are generally thought

Corresponding author: Dr. Anuradha Mishra

Associate Professor, Faculty of Pharmacy, Integral University, Lucknow-226026, Uttar Pradesh, India

E-mail: mishra.anuradha@gmail.com

Tel.: +91-7376550091

Copyright (ㅇ 2021 Ukaaz Publications. All rights reserved.

Email: ukaaz@yahoo.com; Website: www.ukaazpublications.com to be harmless because they come from natural sources. Herbal medicine has grown in popularity as a result of the toxicity and side effects of allopathic medicines, resulting in a rapid expansion in the number of herbal drug makers (Pathak and Das, 2013). Many drugs have originated from plant sources, so there is a plant Trigonella foenum-graecum L. used for various purposes.

Fenugreek (Trigonella foenum-graecum L.) is a leguminous plant of Fabaceae family and is generally cultivated in certain countries like Mediterranean, Europe, Argentina, Egypt, and northern India (Jiang et al., 2007). The fenugreek seeds were known for their bitter taste and the cause of bitterness, due to the presence of saponins, which restrict their use in food. The seeds can be debittered by different processing techniques such as sprouting the seeds, soaking and roasting (Pandey and Awasthi, 2015). Flowers of fenugreek are white to yellowish-white in color and with five petals known as the banner, wing, and keel. Whereas, the pollens are circular in form (Basu, 2006; Montgomery, 2009; Mehrafarin et $a l ., 2011)$. The fenugreek flower produces 2-8 brownish-toyellowish brown pods that are about $15 \mathrm{~cm}$ long. Each pod contains ten to twenty seeds (Ahmad et al., 2016). Methi seeds are largely used due to their antidiabetic effects and gustatory, the food material in Iran and India (Kia et al., 2018). Fenugreek seeds are copious with fibers as well as flavonoids such as, quercetin, apigenin, isovitexin, vitexin, luteolin, and orientin. The natural antioxidants found in seeds are helpful to improve the immune system, promote cellular health, and curtail the ageing signs. It also contains diosgenin, saponin fenugrin B, alkaloids such as trigonelline, gentianine, carpaine as well as many coumarin constituents have been found in fenugreek (Chatterjee et al., 2010). Important phytoconstituents from fenugreek, responsible for medicinal claims are polyun saturated fatty acids, saponins, trigonelline, galactomannans, and 4-hydroxy isoleucine. Flavonoids Apigenin 6, 8-di-C-glucoside, apigenin-6-C-glucosyl-8-C-galactoside, 6-C galactosyl- 8-C- 
arabinoside are the chief ingredients of fenugreek seeds (Sahar et al., 2021). Few components are mentioned in Figure 1.

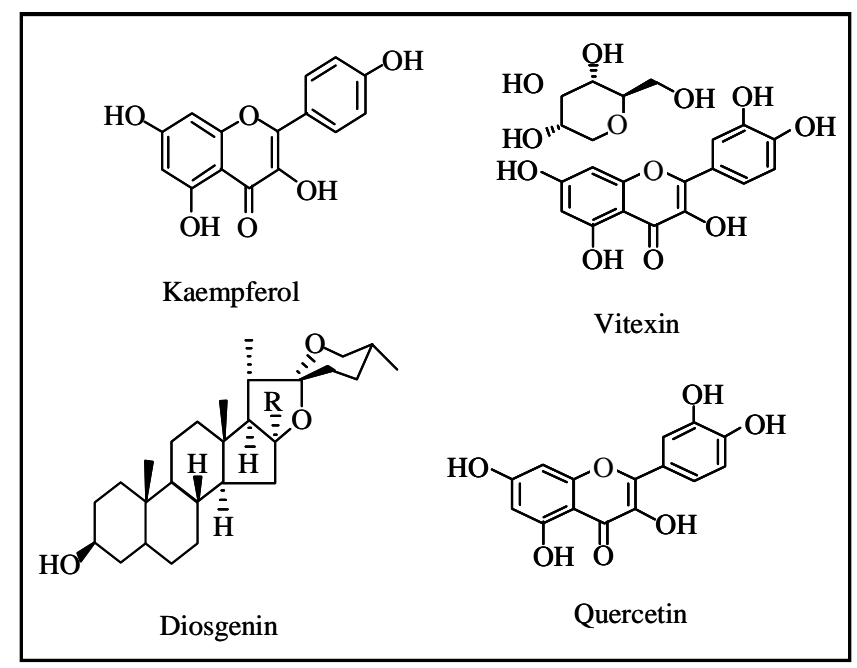

Figure 1: Important phytoconstituents fron Fenugreek.

Fenugreek is a very common and advantageous herb in Ayurveda and Unani medicine system which is utilized for various allergic and inflammatory diseases such as seizures, hemorrhoids, palsy, gout, dropsy, and persistent cough (Bae et al., 2012). Many research study explains that fenugreek utilized for the therapy of breast cancer (Amin et al., 2005; Khoja et al., 2011; Alshatwi et al., 2013), connective tissue cancer (Das et al., 2012), skin cancer (Ali et al., 2014), cataract (Gupta et al., 2009), and act as hepatoprotective (Zargar, 2014), hypolipidemic, antibiotic, antiplasmodic, anthelmintic, anti-inflammatory, and analgesic agent. It also controls the ulcer, various carcinomas, improve fertility, antioxidant activity and work as immunomodulator and modify the enzymatic pathways (Bahi et al., 2017).

\section{Materials and Methods}

2.1 Collection and authentication of Trigonella foenumgraecum L. seeds

Commercially available fenugreek seeds (Trigonella foenum-graecum L.) are collected from the local market of Aminabad, Lucknow, India. The taxonomic authentication was done by the Scientist of Botany and Pharmacognosy, CSIR, Lucknow, India and the voucher specimen (Accession No. is T025, having reference number CIMAP/ Bot-Pharm/2018/11) was deposited to Botany and Pharmacognosy, CSIR, Lucknow. Seeds were used to study macroscopic and microscopic characters. The seeds were coarsely powdered and utilized to determine the ash values and conduct preliminary phytochemical analysis as per norms

\subsection{Germination of fenugreek seeds}

$50 \mathrm{gm}$ of fenugreek seeds were collected, cleaned, and washed with water, dried in air for $1 \mathrm{~h}$, then elutriate in water for $6 \mathrm{~h}$ at room temperature $\left(27-30^{\circ} \mathrm{C}\right)$. The steeped seeds are maintain between a thick layer of cotton fabric and allowed to sprout for 4-5 days in dark at room temperature. During this time, the fabric and seeds are moistened by sprinkling the water. Then after 5 days, germinated seeds were dried for further processing. Germination of fenugreek seeds was exerted to phytochemical analysis as shown in Figure 2.

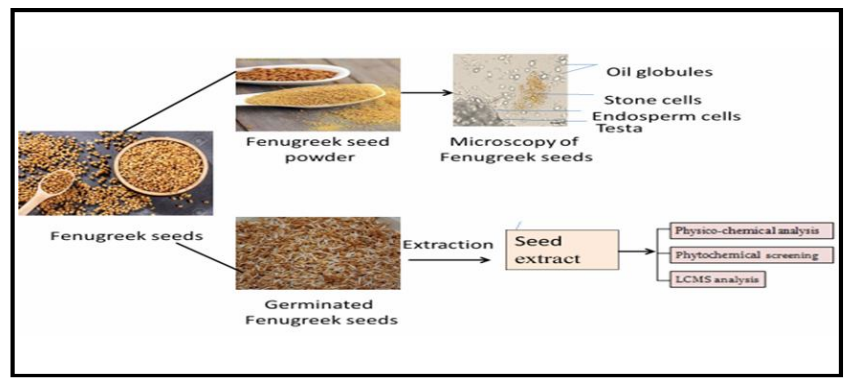

Figure 2: Steps of phytochemical analysis done.

\subsection{Preparation of germinated fenugreek seed extract}

50 gm coarsely powdered seeds of germinated $T$. foenum-graecum were extracted with ethanol $(70 \%)$ in a Soxhlet apparatus for 4 days. Then extract was filtered and the filtrate was evaporated until it was completely dry. The percentage yield of ethanolic extract was calculated and stored for further study. The percentage yield of ethanolic extract was calculated and stored for further study.

\subsection{Macroscopic and microscopic studies}

The macromorphology of the seeds was studied as per ideal procedure (Ewans, 2002). Germinated seeds of fenugreek were transversely cut and mounted for Microscopy. Further, germinated seeds were powdered and mounted according to usual microtechniques. The picture was taken with microscope for photo documentation were figured in Figure 3 .

\subsection{Extractive value}

Extractive value can be defined as the quantity of an extract that a plant material yields in a given solvent. Various solvents were used for analysis according to their solubility. The plant material extracted with several different solvents in according to the type of the constituents to be analyzed. Generally, petroleum ether, chloroform, alcohol and aqueous solvents were used for the extraction of crude drugs. Alcohol-soluble extractives were used for crude drugs containing tannins, glycosides, resins, etc. Ether-soluble extractives are used for volatile and fat constituents from drugs. The petroleum ether extracts contains fixed oil, volatile substances, and resins but when the extract is heated at $105^{\circ} \mathrm{C}$, until constant weight, the volatile contents are evaporated leaving only resin, colouring matter and fixed oil (Shah and Seth 2009; Indian Pharmacopoeia, 1996).

\subsection{Total ash}

Total ash content required for detection of the crude drugs in mixed with various mineral substances like sand, soil, chalk powder, calcium oxalate, or presence of different inorganic contents, already reported by other researchers. The maximum temperature used for total ash should be not more than $450^{\circ} \mathrm{C}$ because alkali chlorides, may be volatile, would lost at higher temperatures. For evaluation of total ash, 2 gm crude drug was taken in a crucible and was ignited in oven at a temperature not exceeding $450^{\circ} \mathrm{C}$ until free from carbon. It was cooled and then weighed to obtained the total ash content (Kokate et al., 2005; Indian Pharmacopoeia, 1996). 


\subsection{Foreign matter}

The parts and substances other than the parts of drugs mentioned in the definition and description of the drug are known as foreign organic matters. It may be include insect, moulds, earthy material, animal excreta, etc. It was separated from the drug, so that the result obtained from analysis of the drug gives accuracy. Its percentage in the crude drug was calculated (Ansari, 2008).

\section{$2.8 \mathrm{pH}$ determination}

\subsection{1 pH 1\% solution}

$1 \mathrm{gm}$ crude drug was weighed and dissolved in water then filtered. $\mathrm{pH}$ of filterate is checked with a standardized glass electrode.

\subsection{2 pH 10\% solution}

$10 \mathrm{gm}$ crude was weighed and dissolved in water and filtered. $\mathrm{pH}$ of filtrate is checked with a standardized glass electrode (Ansari, 2008).

\subsection{Phytochemical analysis}

Plants contain chemical constituents like carbohydrates, alkaloids, triterpenoids, essential oils, tannins, glycosides flavonoids may be therapeutically active or inactive. Qualitative phytochemical analysis were done using the standard procedures (Kokate, 2005; Ronia et al., 2017).

\subsubsection{Test for sterols}

\section{Salkowaski reaction}

Small quantity of germinated fenugreek seed extracts was treated with few drops of concentrated sulphuric acid and shake well for few minutes. The development of red color indicates the presence of sterols.

\section{Libermann burchard test}

Germinated fenugreek seeds were treated with few drops of acetic anhydride and then boiled and cooled. Then add conc. hydrochloric acid from the side of the test tube. Brown ring is form at the junction of two layers from which upper layer turn green which confirm the presence of sterols and formation of deep red colour shows presence of triterpenoids (Kokate et al., 2005)

\subsubsection{Test for alkaloids}

(a) Dragendorff's reagent test (potassium iodide + bismuth nitrate): Confirmation of presence of alkaloid gives orange red colour precipitate

(b) Mayer's reagent (potassium mercuric iodide solution): The result showed white or pale yellow colour precipitate with only exception with alkaloids/purine.

\subsubsection{Test for saponins}

\section{Foam test}

$10 \mathrm{mg}$ seed extract was taken in a test tube and shaken vigorously with water and a pinch of sodium bicarbonate. A stable and characteristic honeycomb like froth showed, indicates the presence of saponins (Ansari and Deepika, 2007)

\subsubsection{Test for flavonoids}

To the ethanolic seed extract of fenugreek add magnesium and slowly add concentrated hydrochloric acid to show pink, crimson red and further color change was observed from green-to-blue colour after few minutes

\subsubsection{Test for phenolic compounds}

\section{Ferric chloride solution}

Germinated Trigonella seed extracts was warmed with $0.5 \mathrm{ml}$ of water, then add $2 \mathrm{ml}$ of ferric chloride solution. The obtained green or blue color confirmed the presence of phenolic compounds.

\section{Lead acetate solution}

Germinated seed extracts was added in lead acetate solution. The formation of precipitate confirmed the presence phenolic compounds (Kokate et al., 2005).

\subsubsection{Test for glycosides}

\section{Killer killiani test}

$1 \mathrm{ml}$ of concentrated sulphuric acid and $1 \mathrm{ml}$ of glacial acetic acid containing traces of ferric chloride were added to seed extracts. The formation of reddish brown color junction and then it turns into bluish green color in presence of glycosides (Ansari, 16 th edition).

\subsubsection{Test for carbohydrate}

(a) Fehling's solution test: $0.5 \mathrm{gm}$ extracts were heated with dilute hydrochloric acid to hydrolyze a polysaccharide. The reaction mixture is neutralized by addition of sodium hydroxide solution and then Fehling solution 1 and 2 were added. Red precipitate was formed in case of reducing sugar while nonreducing sugars produce red color after boiling with acid.

(b) Molisch's test: Small quantity of seed extracts was treated with alpha nephthol and concentrated sulphuric acid. It produce purple ring is formed on the junction below aqueous layer (Arumugam and Murugesh, 2004)

\subsubsection{Test for protein and free amino acid}

\section{Biuret test}

$2 \mathrm{ml}$ of fenugreek seed extract was added dropwise to a diliute solution of copper sulphate. A red or violet colour is formed with peptides containing at least two peptide linkage.

\section{Millon's test}

It is a mixture of mercuric nitrate in nitric acid containing a trace of nitrous acid. It gives white precipitate which turns red on heating (Ali, 2004).

\subsection{Physicochemical analysis}

Extractive values of fenugreek extract, total ash, foreign matter, and moisture content were carried out according to the standard methods (Arif and Fareed, 2010). A calibrated digital pH meter was used to measure the $\mathrm{pH}$ of 1 and $10 \%$ aqueous extract.

\subsection{UV spectrophotometry}

UV visible spectroscopy for estimation of rutin and quercetin from plant extract were carried out. Standard curve of quercetin and 
rutin were prepared by dissolving $5 \mathrm{mg}$ of quercetin and rutin in 5 $\mathrm{ml}$ of ethanol. Then, the solution was diluted to 20,40,60, 80 and $100 \mu \mathrm{g} / \mathrm{ml}$ concentration. Standard graph was prepared using Schimadzu UV-visible spectrophotometer and absorbance was recorded at 362 and $425 \mathrm{~nm}$ for rutin and quercetin respectively. Then, the fenugreek seeds extract was prepared in ethanol and the absorbance was taken at $362 \mathrm{~nm}$ and $425 \mathrm{~nm}$. Standard graph of extract was done using $362 \mathrm{~nm}$ and $425 \mathrm{~nm}$ separately graph mentioned in Figure 4 (Kurzawa, 2010; Kagawad et al., 2021).

\subsection{Thin-layer chromatography (TLC)}

Analytical chromatography was completed to discover a appropriate solvent system for the visualization of chromatogram. Analysis was performed on preparative aluminium-backed silica gel 60F-254 plates ( $0.25 \mathrm{~mm}$, Merck, Darmstadt, Germany). Before utilization, the plates were pre-cleaned with methanol and dried in fume hood. Then, standard (quercetin) and test (Fenugreek extract) solutions were applied to the plates. Various mobile phases were tried for the analysis such as butane: methanol: acetic acid: water (5:3:1.5:0.5), ethyl acetate: glacial acetic acid: methanol: water (8:0.5:0.5:1) and ethyl acetate: methanol: water $(7: 2: 1)$. The spots of standard and test samples were analyzed under visible light and calculate the Rf values.

\subsection{LCMS analysis}

Liquid Chromatography and Mass Spectroscopy (LCMS) was carried out for identification of secondary metabolites. Here Trigonella seed extract was mixed with standard bioactive, i.e., quercetin and rutin for qualitative and quantitative analysis under standard conditions.

\section{Results}

\subsection{Macroscopical characters}

The fenugreek seed is oblong in shape. Seeds consist of yellow hard embryo which is covered by a corneous and comparatively large white layer of semi-transparent endosperm, that contains the galactomannan gum (Naidu et al., 2011). Seeds are small (4 $5 \mathrm{~mm}$ long), hard, smooth, dull yellow to brownish-yellow in color. The widest surface is marked by a groove that divides the seeds into two unequal parts, in which small part contains radical and the larger one contains cotyledons (Ahmad et al.,2016 ; Indian Pharmacopoeia, 2018). The flavor of seeds is mucilaginous and slightly bitter (Gupta et al., 2006).

\subsection{Microscopic characters}

The seeds were coarsely powdered and then used for microscopy. The microscopic result suggests that the seeds consist of cuticle, epidermis, hypodermis, and parenchymatous cells. Seeds also have an endosperm having outermost cells and mucilage cells. Methi seeds contain oil globules, calcium, and aleurone grains; it also contains testa which is composed of thick-walled, cylindrical lignified cells with conical projections. The middle layer of the testa is composed of cells with thick-walled and wide intercellular spaces near their tops. The cotyledons consist of 3-4 layers of palisade cells varying in size with a long axis and a few layers of rudimentary 6 spongy tissue as shown in Figure 3.

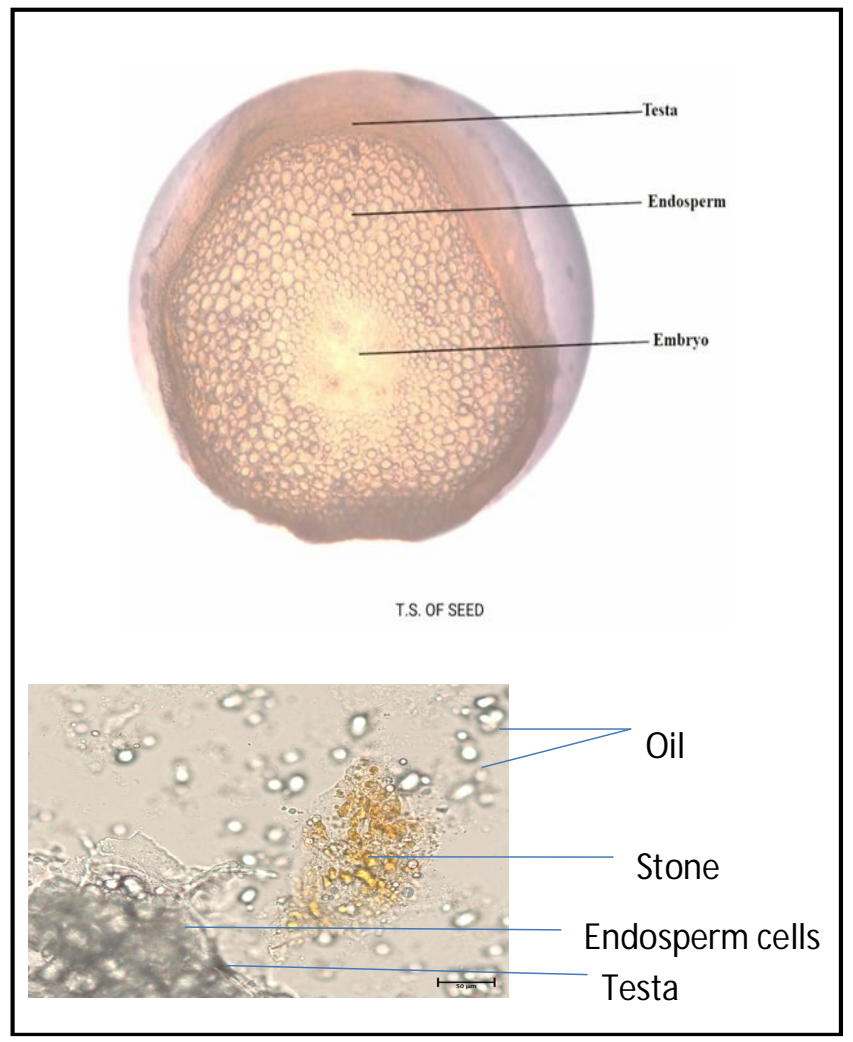

Figure 3: TS of fenugreek seed and its powder microscopy.

\subsection{Parameters assessed}

The physicochemical characters of the powdered seeds of $T$. foenumgraecum such as ethanol, ash value, water-soluble ash, and foreign matter are presented in Table 1.

Table 1: Extractive values of quantitative parameters

\begin{tabular}{|l|c|}
\hline Quantitative parameter & Value obtained \% (w/w) \\
\hline Ethanolic extractive value & 13 \\
\hline Water-soluble ash & 5 \\
\hline Total ash & 3.8 \\
\hline Foreign matter & 0.22 \\
\hline
\end{tabular}

The $\mathrm{pH}$ of 1 and $10 \%$ aqueous solution was found to be 5.38 and 5.22 , respectively.

\subsection{Preliminary phytochemical screening}

The preliminary phytochemical investigation of ethanolic extract of fenugreek seeds showed the presence of flavonoids, alkaloids, saponins, phenolic content, carbohydrate, glycosides, sterols, proteins, and amino acids shown in Table 2.

3.5 Results of UV spectrometry, thin layer chromatography (TLC) and liquid chromatography-mass spectroscopy (LCMS) analysis

From the UV visible spectroscopy of pure quercetin and rutin, we observed similar curve for rutin and quercetin as it was shown equation curve, $\mathrm{y}=0.0081 \mathrm{x}-0.0192$ and $\mathrm{R}^{2}=0.9901$ and for quercetin was $y=0.007 \mathrm{x}-0.0433$, and the $\mathrm{R}^{2}$ value was 0.99 were same as 
mentioned in reports (Ahuja and scypinski, 2001). The estimated equation of calibration was $y=0.0016 x+0.0016$ and the Regression coefficient of $R^{2}=0.9977$. Further, the concentration of rutin was $7.9 \mu \mathrm{g} / \mathrm{ml}$ and quercetin was $8.38 \mu \mathrm{g} / \mathrm{ml}$, detail of standard graph figured in Figure 4.

Table 2: Phytochemical reports of ethanolic seed extract of T. foenum-graecum

\begin{tabular}{|c|l|c|}
\hline S. No. & Tests & Ethanolic extract \\
\hline $\mathbf{1 .}$ & $\begin{array}{l}\text { Flavonoids test } \\
\text { Ammonia test }\end{array}$ & + \\
\hline $\mathbf{2 .}$ & $\begin{array}{l}\text { Alkaloid test } \\
\text { Dragendroff's reagent } \\
\text { Mayer's reagent }\end{array}$ & + \\
\hline $\mathbf{3 .}$ & $\begin{array}{l}\text { Saponin test } \\
\text { Foam test }\end{array}$ & + \\
\hline $\mathbf{4 .}$ & Carbohydrate test & + \\
\hline $\mathbf{5 .}$ & $\begin{array}{l}\text { Fehling solution test } \\
\text { Molish test }\end{array}$ & + \\
& $\begin{array}{l}\text { Ferric chloride test } \\
\text { Lead acetate test }\end{array}$ & + \\
\hline $\mathbf{6 .}$ & Sterols test & + \\
& $\begin{array}{l}\text { Salkowaski test } \\
\text { Libermann-buchard test }\end{array}$ & + \\
\hline $\mathbf{7 .}$ & Glycoside test & + \\
\hline & Keller-killiani test & + \\
\hline & Mest for proteins and free & + \\
\hline
\end{tabular}

(+ indicates present and - indicates absence)

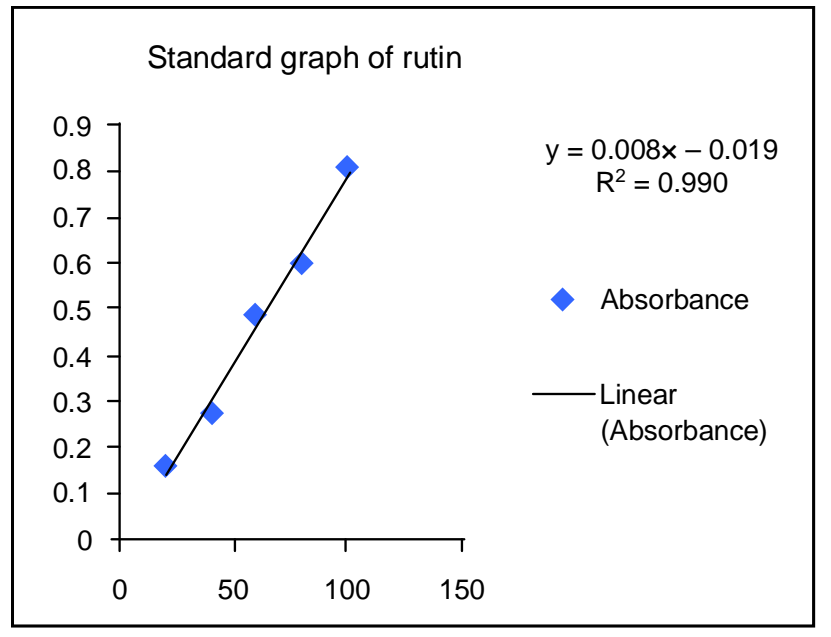

(a)

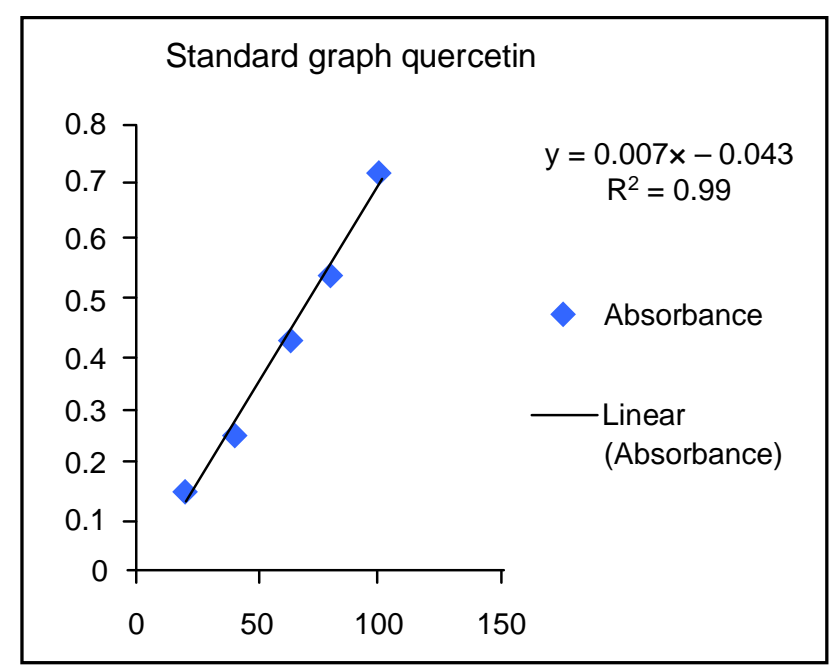

(b)

Figure 4 : Standard graph of (a) rutin and (b) quercetin.

Preliminary TLC was carried out using preparative TLC plates. In this research, we have selected 3 different solvent systems. We observed 3 spots while using ethyl acetate: methanol: water in ratio (7:2:1) for fenugreek ethanolic extract and the details mentioned in Table 3. Further, the observed Rf values were $0.46,0.7$ and 0.8 . Out of which, 0.46 was the same Rf as similar to that of quercetin.

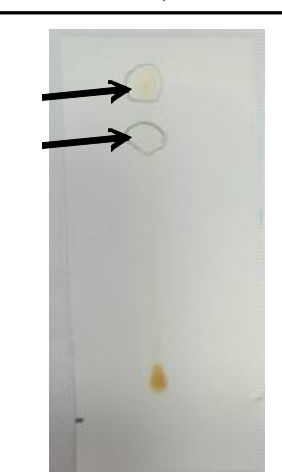

a

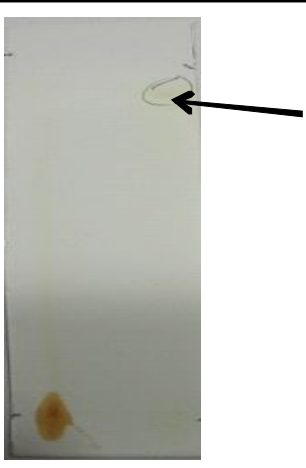

b (a) An example of thin-layer chromatography (TLC) performed by fenugreek extract, (b) an example of thin layer chromatography (TLC) performed by pure quercetin

Figure 5: TLC findings using quercetin as standard.

Table 3: Paper TLC of germinated fenugreek seed extract

\begin{tabular}{|c|l|c|c|c|}
\hline S.No. & Mobile phase & Ratio & $\begin{array}{c}\text { No. of } \\
\text { spots } \\
\text { obtained }\end{array}$ & Rf \\
value \\
\hline 1 & $\begin{array}{l}\text { butane: methanol: } \\
\text { acetic acid: water }\end{array}$ & $5: 3: 1.5: 05$ & No spot & 00 \\
\hline 2 & $\begin{array}{l}\text { ethyl acetate: } \\
\text { glacial acetic acid: } \\
\text { methanol: water }\end{array}$ & $8: 0.5: 0.5: 1$ & 1 spot & 0.8 \\
\hline 3 & $\begin{array}{l}\text { acetate: methanol: } \\
\text { water }\end{array}$ & $7: 2: 1$ & 3 spot & $\begin{array}{c}0.46, \\
0.7,0.8\end{array}$ \\
\hline
\end{tabular}


whereas, liquid chromatography mass spectroscopy was done using rutin and quercetin as standard and the results were mentioned in
Table 4, Further, the findings confirmed the presence of rutin and quercetin in ethanolic seed extract of $T$. foenum-graecum.

Table 4: Chemical constituents present in germinated fenugreek seeds

\begin{tabular}{|l|l|c|c|c|}
\hline Part used & Chemical constituent & Analyte peak area (counts) & Retention time (min) & Height (cps) \\
\hline Standard compound & Rutin & 9973.897 & 8.113 & 1419.031 \\
Seeds extract & Rutin & 3353.378 & 8.110 & 369.803 \\
Standard compound & Quercetin & 102395.416 & 8.444 & 7212.343 \\
Seeds extract & Quercetin & 76550.714 & 8.443 & 5249.995 \\
\hline
\end{tabular}

LCMS data reveals that rutin and quercetin are present in the ethanolic extract of germinated fenugreek seeds as the retention time is same as that of standard drug.

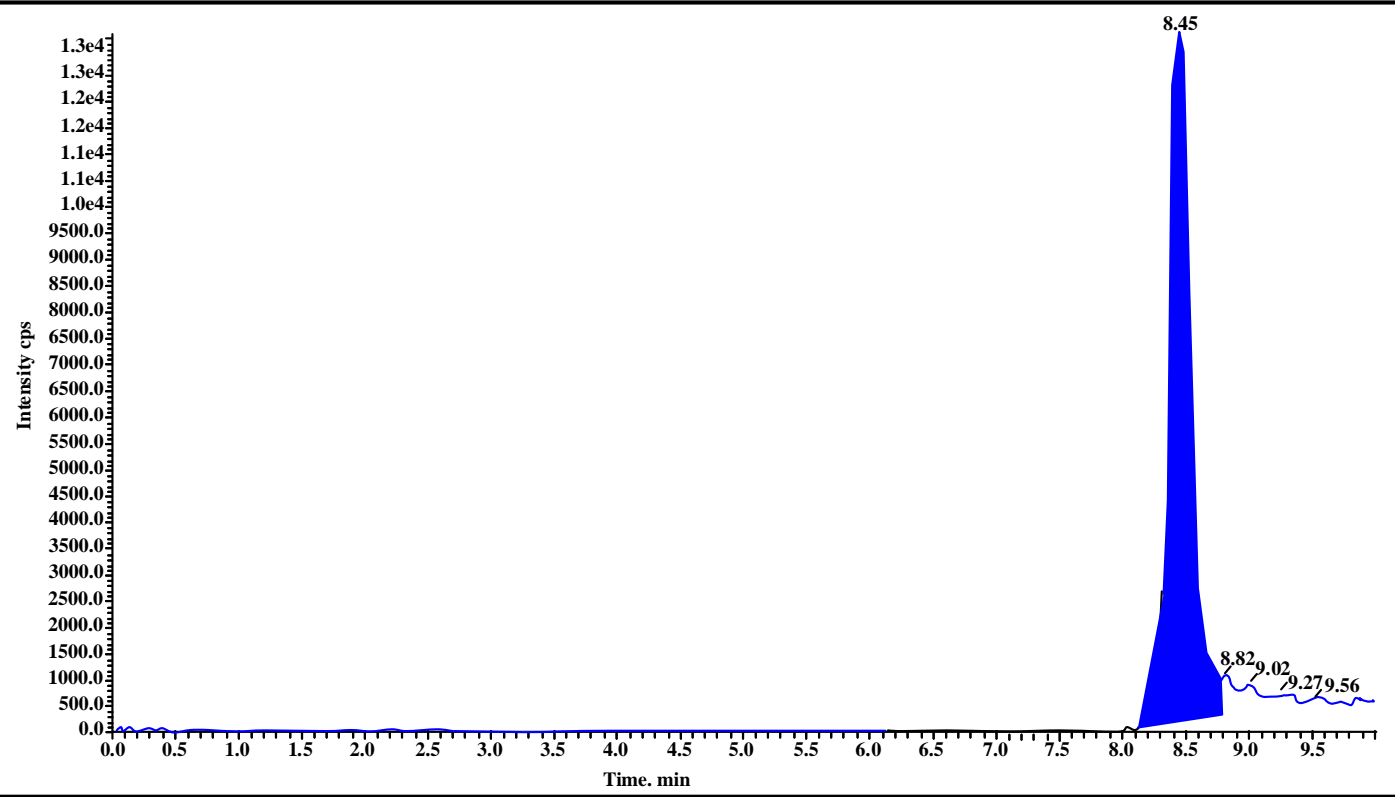

(a) Quercetin peak (standard)

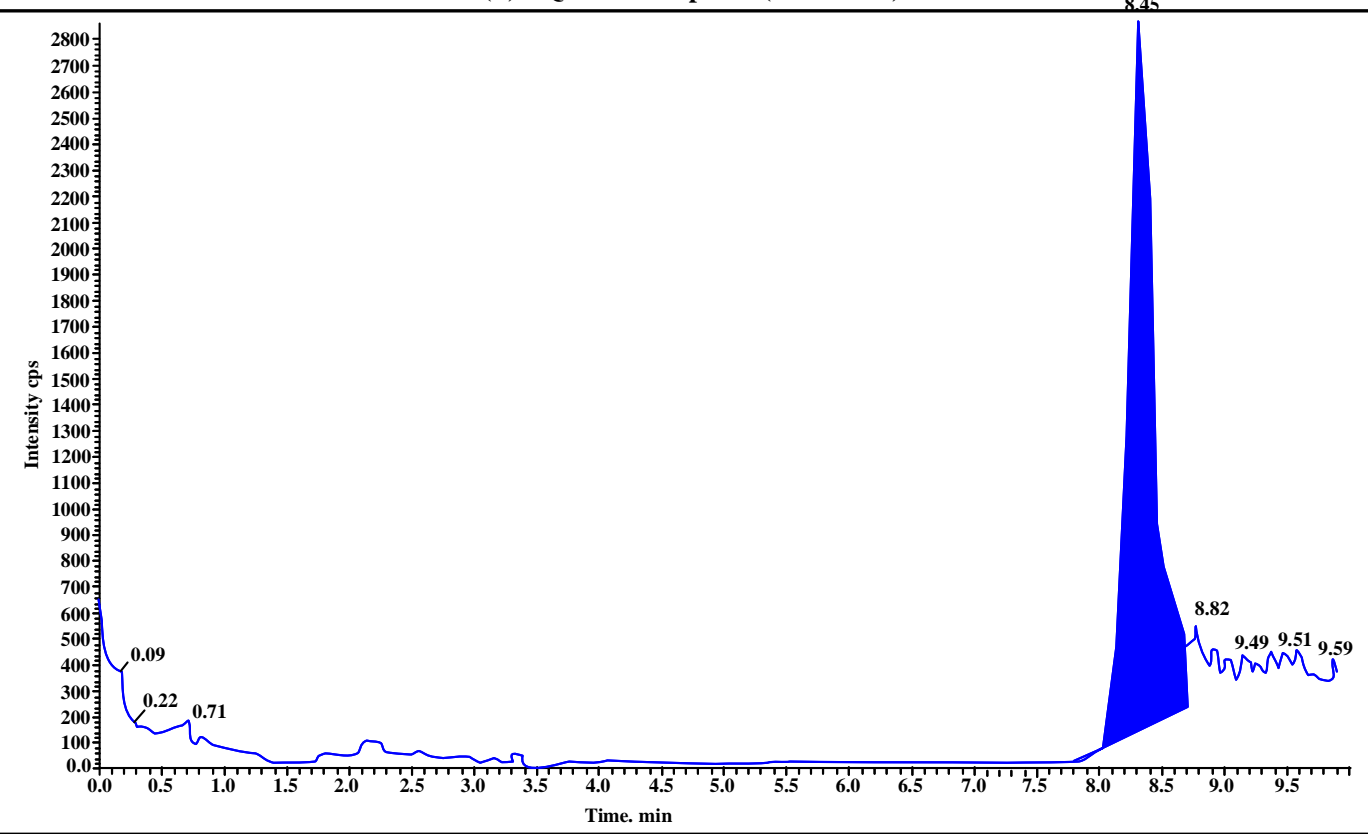

(b) Quercetin peak of fenugreek exract 


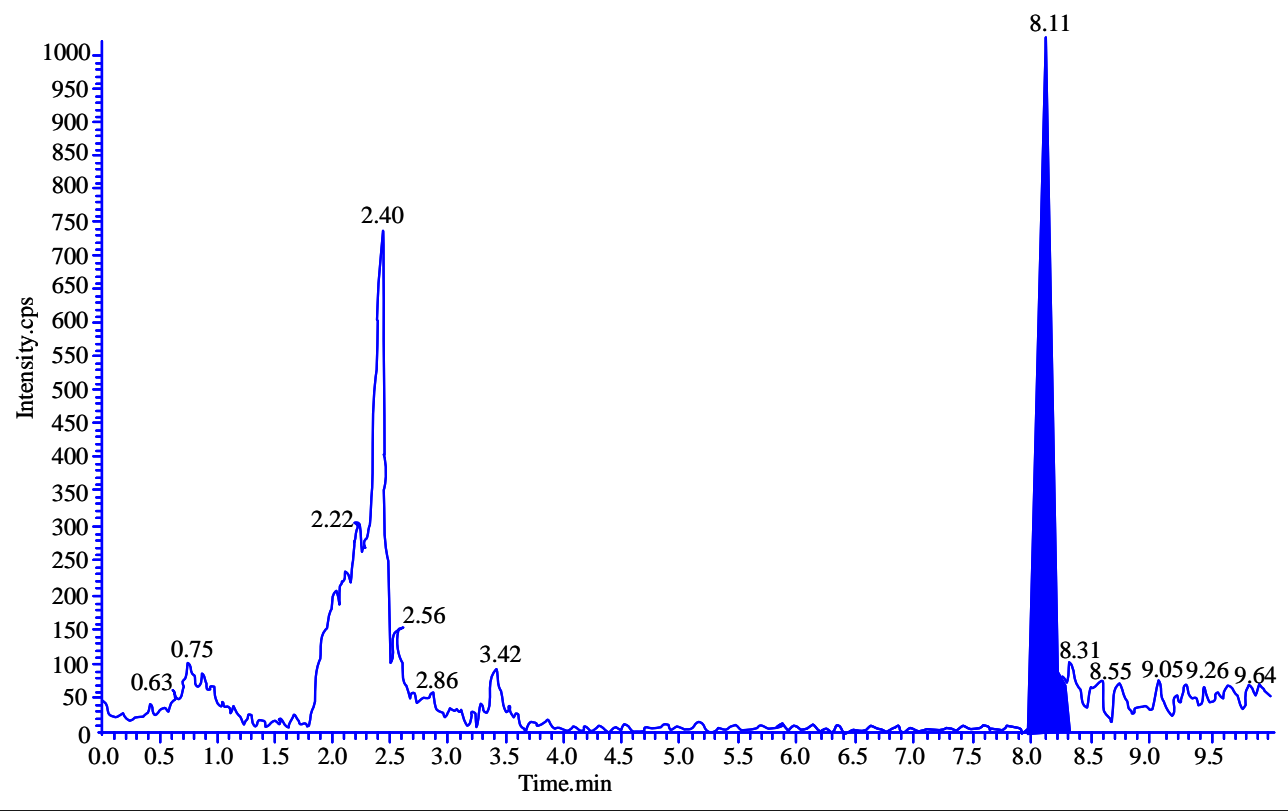

(c) Rutin peak (standard)

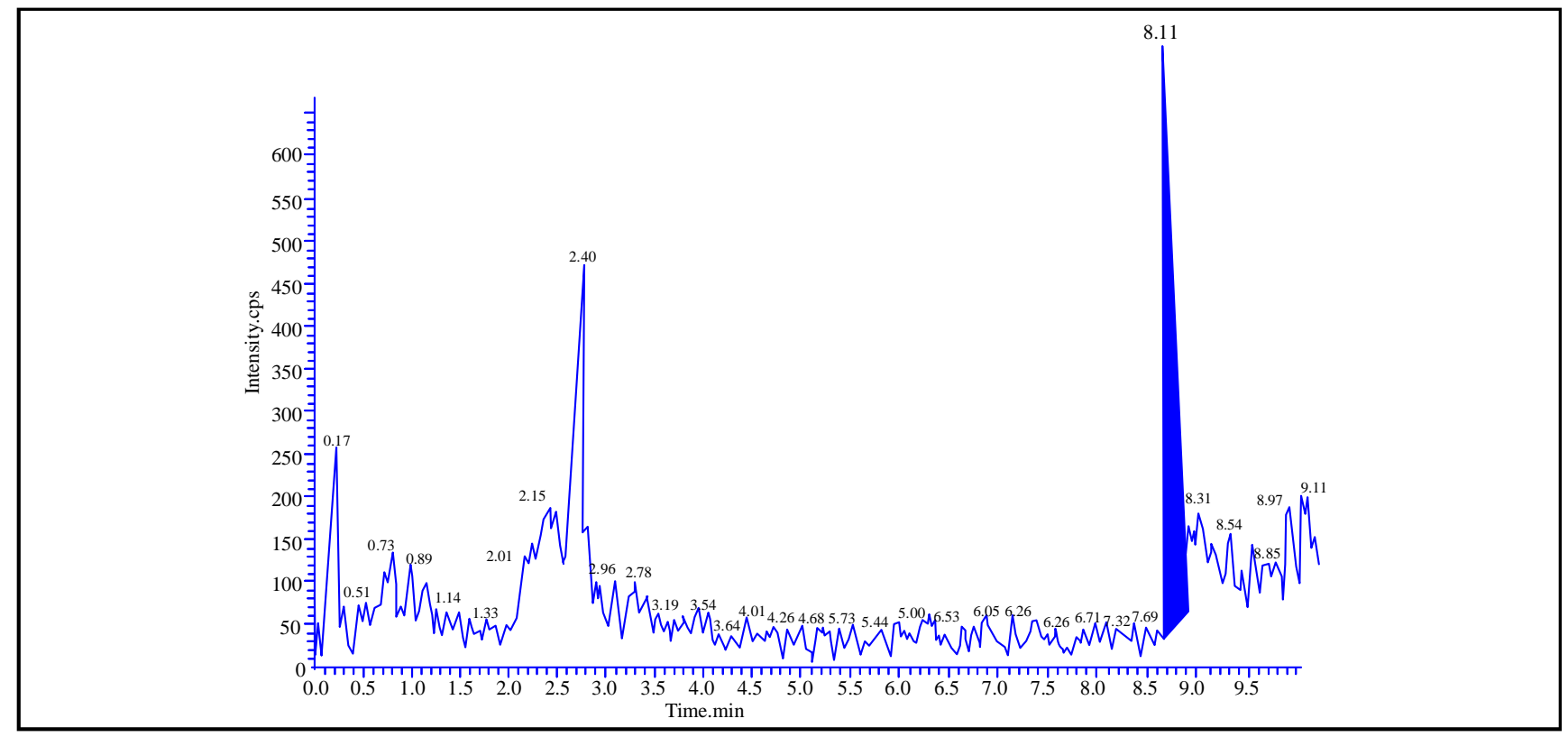

(d) Rutin peak of fenugreek extract

Figure 6: LCMS images of standard samples of quercetin and rutin and $T$. foenum-graecum germinated seed extract.

So from Figure 5 and Table 4, it has been confirmed that ethanolic seed extract of fenugreek contains quercetin and rutin in observed concentration.

The results showed a comparative findings of presence of rutin as obtained at $\mathrm{RT}=8.110$, as that of standard rutin, while quercetin in the seed extract of Fenugreek at Rt $=8.443$ Similarly, as that of standard but further the peak indicates the concentration of quercetin is 17 fold higher than that of rutinin ethanolic extract of fenugreek seeds.

\section{Discussion}

It is known that plants are very common source of chemical compounds that fall under primary and secondary metabolites. Primary metabolites are required for growth and cellular functions of the plant while secondary metabolites protect the plants from microbes, viruses or competing plants and function as signal compounds to attract pollinating or seed dispersing animals (Nanusha et al., 2020). Preliminary phytochemical and physicochemical screening were carried out to ensure their purity and 
presence of secondary metabolite to be utilized as a drug. From the phytochemical screening and quantitative estimation of the percentage crude yields of chemical constituents of the plants confirmed that the selected extract is rich in flavonoids and phenolic compounds. Interestingly, flavonoids, alkaloids, sterols, saponins and steroids are present in fenugreek seeds which supposed to be of maximum medicinal value as it possesses majority of identified phytoconstituents.

Flavonoids are important metabolite which possess antioxidant and free radical scavenger property that prevent the cells from oxidative damage and also have strong anticancer activity (Benavente-García et al., 1997; Salah et al., 1995). Tannins have stringent properties which have wound healing action and protect inflamed mucous membranes (Doss, 2004). Terpenoids responsible for the treatment of cancer, antihyperglycemic, anti-inflammatory, antimicrobial, antifungal, antiallergenic, antiviral, antispasmodic and immune-modulatory properties (Rabi et al., 2009; Wagner et al., 2003).

Analytical TLC was performed to find out a suitable solvent system for the development of chromatogram. Many solven system such as toluene: acetone: the glacial acetic acid (45:45:10) (Dharajiya et al., 2016), toluene, ethyl acetate, chloroform and methanol (9.5:0.5, 9:1, 7:3, 1:1.) (Sambandam et al.,2016), chloroform : methanol : water (65:35:5) (Gad et al., 2006) for the quercetin. Our study suggests that ethyl acetate: methanol: water $(7: 2: 1)$ gives best results and give 3 spots at $0.46,0.7,0.8 \mathrm{Rf}$ values which confirms the presesnce of quercetin in fenugreek extract.

Mass spectrometry is very effective technique for the analysis of flavonoids owing to its high sensitivity and the possibility of coupling with different chromatographic techniques such as LC/ MS. LC/MS analysis allows both qualitative and quantitative determinations.

The second part of our study carried out liquid chromatography mass spectroscopy and confirm the presence of flavonoids rutin and quercetin. Rutin is a water-soluble flavonoids, antioxidant which converts to quercetin in the bloodstream (Azevedo et al.,2013). Quercetin is popular antioxidant agent which prevents oxidant injury and cell death by scavenging free oxygen radicals. The anti inflammatory action is due to inhibitory effects on cyclooxygenase, lipoxygenase, inflammatory mediators, including leukotrienes and prostaglandins (Kim et al., 1998). Rutin has many pharmacological activities, including antioxidant, cytoprotective, vasoprotective, anticarcinogenic, neuroprotective and cardioprotective activities. (Ganeshpurkar and Saluja, 2017).

Some research article shows the presence of rutin and quercetin in plant extract which was confirmed by LCMS technique (Chang et $a l ., 2012$ ) perform the study to examine the presence of six flavonoids content: sophoricoside, genistin, genistein, rutin, quercetin and kaempferol in Fructus sophorae extract and result explains that all flavonoids are present in the extract specially rutin and quercetin in high amount in 5.23 and $5.83 \mathrm{~min}$ of retention time. Other study was made by He et al. (2013) to identify the 6 flavonoids (rutin, isoquercitrin, astragalin, quercetin, kaempferol and isorhamnetin) in mulberry leaves and the findings suggest that out of 6 flavonoids, the higher AUC $(755.03 \pm 468.23)$ was found for quercetin as compared to other flavonoids. Many other research studies confirm the presence of quercetin, kaempferol, rutin, glabridin, and naringenin in various plants such as galanga (Alpinia officinarum Hance) rhizomes (Moringa oleifera L.), lucerne (Medicago sativa L.), goldenrod (Solidago virgaurea L.), phacelia (Phacelia tanacetifolia Benth.), buckwheat (Fagopyrum esculentum L.), licorice (Glycyrrhiza glabra L.), and lavender (Lavandula spica L.) by LCMS, LCMS/MS and SLE-SPE-UHPLC-MS/MS methods (Kose et al., 2015; Coppin et al., 2013; Bajkacz et al., 2018).

Sulaiman et al. (2016) investigated the presence of flavonoids in $T$. involucrata $\mathrm{L}$. and findings suggest that the plant is rich in as iridin, dihexosyl quercetin, quercetin-3-O-rutinoside, rhamnosyl hexosyl methyl quercetin, gentenstein 7-glucoside, orientin, C-(O-caffeoylhexosyl)-O-hexoside and tricin 7-O-hexosyl-O-hexoside were identified by LCMS technique (Sulaiman et al., 2016).

From the result, standard quercetin shows peak 8.45 at $8.450 \mathrm{~min}$ retention time (Area: 157381.359 counts Height; $13046.069 \mathrm{cps}$ ) whereas fenugreek show peak at 8.45 at 8.452 min retention time which covers 39124.101 counts area and height of peak measure to be $2752.339 \mathrm{cps}$. These findings confirm the presence of quercetin in ethanolic extract of fenugreek seeds.

Standard rutin shows 8.11 peak at 8.114 min which covers 4110.623 (counts) area and height $591.510 \mathrm{cps}$. Whereas, ethanolic extract of fenugreek seeds show 8.11 peak at 8.10 retention time which covers 7144.501 (counts) area and peak height is measure $1011.835 \mathrm{cps}$.

\section{Conclusion}

Phytochemical standardization of plant material is essential to determine the pharmacological activity, therefore present research focuses on the pharmacognostical and phytochemical examination of germinated $T$. foenum graecum seeds. These parameters are essential to determine the quality, potential, and safety of the drug. The result of the present study suggests that fenugreek seeds contain quercetin and rutin as phytoconstituents which play a vital role in controlling and treatment for various diseases. The preliminary phytochemical study reveals that fenugreek seeds are rich in carbohydrates, flavonoids, alkaloids, glycosides, proteins, and amino acids which provide nutrition and make the body healthy.

\section{Acknowledgments}

The authors offer their sincere thanks to Professor Syed Waseem Akhtar, Hon. Chancellor and Vice Chancellor for providing excellent research facility in the University and Chairman, Research and Development, Integral University, for his valuable suggestion and assigning Communication Reference No: IU/R\&D/2020MCN000XXX, for further communication.

\section{Conflict of interest}

The authors declare no conflicts of interest relevant to this article.

\section{References}

Ahmad, A.; Alghamdi, S.S.; Mahmood, K. and Afzal, M. (2016). Fenugreek a multipurpose crop: Potentialities and improvements, Saudi J. Biol. Sci., 23:300-310

Ahuja, S. and Scypinski, S. (2001). Modern pharmaceutical analysis: An overview. Handbook of Modern Pharmaceutical Analysis, 3:1-4.

Ali, F.; Khan, R.; Khan, A.Q.; Lateef, M.A.; Maqbool, T. and Sultana, S. (2014). Assessment of augmented immune surveillance and tumor cell death by cytoplasmic stabilization of p53 as a chemopreventive strategy of 3 promising medicinal herbs in murine 2-stage skin carcinogenesis. Integr. Cancer Ther., 13:351-367. 
Ali, M. (2004). Text book of pharmacognosy. $2^{\text {nd }}$ edition, CBS publishers. Al-Jenoobi, F.I.; Alam, M.A.; Alkharfy, K.M.; Al-Suwayeh, S.A.; Korashy, H.M.; AlMohizea, A.M.; Iqbal, M.; Ahad, A. and Raish, M. (2014). Pharmacokinetic interaction studies of fenugreek with CYP3A substrates cyclosporine and carbamazepine. Eur. J. Drug Metab. Pharmacokinet., 39:147153.

Alshatwi,A.A.; Shafi, G; Hasan, T.N.; Syed, N.A. and Khoja, K.K. (2013). Fenugreek induced apoptosis in breast cancer MCF-7 cells mediated independently by fas receptor change. Asian Asian Pac. J. Cancer Prev., 14:5783-5788.

Amin, A.; Alkaabi, A.; Al-Falasi, S. and Daoud, S.A. (2005). Chemopreventive activities of Trigonella foenum-graecum (Fenugreek) against breast cancer. Cell Biol. Int., 29:687-694.

Ansari, S. H. (2008). Essentials of Pharmacognosy. Birla Publications Pvt. Ltd 1st edition. New Delhi.

Ansari, S.H. and Bhatt, D. (2007). A concise text book of pharmacognosy Birla publication Pvt. Ltd.

Arif, M. and Fareed, S. (2010). Pharmacognostic investigation and authentication of potentially utilized fruit Spondias mangifera (willd). Int. J. Curr. Pharmaceut. Clin Res., 2:31-35.

Aruugam, K.R. and Murugesh, N. (2004). Text book of pharmacognosy, Sathya Publishers, Madurai.

Azevedo, M.I.; Pereira, A.F.; Nogueira, R.B.; Rolim, F.E.; Brito, G.A.; Wong, D.V.T.; Lima-Júnior, R.C.; de Albuquerque Ribeiro, R. and Vale, M.L. (2013). The antioxidant effects of the flavonoids rutin and quercetin inhibit oxaliplatin-induced chronic painful peripheral neuropathy. Mol. Pain, 9:1744-8069.

Bae, M.J.; Shin, H.S.; Choi, D.W. and Shon, D.H. (2012). Antiallergic effect of Trigonella foenum-graecum L. extracts on allergic skin inflammation induced by trimellitic anhydride in BALB/c mice. J. ethnopharmacol., 144:514-522.

Bahi, A.; Guardiola, F.A.; Messina, C.M.; Mahdhi, A.; Cerezuela, R.; Santulli, A.; Bakhrouf, A. and Esteban, M.A. (2017). Effects of dietary administration of fenugreek seeds, alone or in combination with probiotics, on growth performance parameters, humoral immune response and gene expression of gilthead seabream (Sparus aurata L.). Fish Shell Fish Immunol., 60:50-58.

Bajkacz, S.; Baranowska, I.; Buszewski, B.; Kowalski, B. and Ligor, M. (2018) Determination of flavonoids and phenolic acids in plant materials using SLE-SPE-UHPLC-MS/MS method. Food Anal. Methods. 11(12):3563-3575.

Basu, S.K. (2006). Seed production technology for fenugreek (Trigonella foenum-graecum L.) in the Canadian prairies (Doctoral dissertation, Lethbridge, Alta.: University of Lethbridge, Faculty of Arts and Science.

Benavente-García, O.; Castillo, J.; Marin, F.R.; Ortuño, A. and Del, Río J.A. (1997). Uses and properties of citrus flavonoids. J. agric. Food. Chem., 45(12):4505-4515

Chang, L.; Ren, Y.; Cao, L.; Sun, Y.; Sun, Q.; Sheng, N.; Yuan, L.; Zhi, X. and Zhang, L. (2012). Simultaneous determination and pharmacokinetic study of six flavonoids from Fructus Sophorae extract in rat plasma by LC-MS/MS. J. Chromatogr. B., 904:59-64.

Chatterjee, S.; Variyar, P.S. and Sharma, A. (2010). Bioactive lipid constituents of fenugreek. Food Chemistry, 119:349-353.

Coppin, J.P.; Xu, Y.; Chen, H.; Pan, M.H.; Ho, C.T.; Juliani, R.; Simon, J.E. and Wu, Q. (2013). Determination of flavonoids by LC/MS and antiinflammatory activity in Moringa oleifera. J. Funct. Foods, 5(4): 1892-1899.
Das, S.; Dey, K.K.; Dey, G; Pal, I.; Majumder,A.; Maitichoudhury, S.; Kundu S.C. and Mandal, M. (2012). Antineoplastic and apoptotic potential of traditional medicines thymoquinone and diosgenin in squamous cell carcinoma. PLoS One, 7:e46641

Dharajiya, D.; Jasani, H.; Khatrani, T.; Kapuria, M.; Pachchigar, K. and Patel, P. (2016). Evaluation of antibacterial and antifungal activity of fenugreek (Trigonella foenum-graecum) extracts. Int. J. Pharm. Pharm. Sci., 8(4):212-217.

Dharajiya, D.; Jasani, H.; Khatrani, T.; Kapuria, M.; Pachchigar, K. and Patel, P. (2016). Evaluation of antibacterial and antifungal activity of fenugreek (Trigonella foenum-graecum) extracts. Int. J. Pharm. Pharm. Sci., 8(4):212-217.

Doss, A. (2009). Preliminary phytochemical screening of some Indian medicinal plants. Anc. Sci. Life, 29(2):12.

Ewans, W.C. (2002). Trease and Evans. Pharmacognosy, Saunders Edinburgh, London, pp:292.

Gad, M.Z.; El-Sawalhi, M.M.; Ismail, M.F. and El-Tanbouly, N.D. (2006). Biochemical study of the antidiabetic action of the Egyptian plants Fenugreek and Balanites. Mol. Cell. Biochem., 281(1):173-183.

Ganeshpurkar, A. and Saluja, A.K. (2017). The pharmacological potential of rutin. Saudi Pharm. J., 25(2):149-164.

Gupta, A.K.; Tondon, N. and Sharma, M. (2006). Quality standards of Indian medicinal plants. Indian Council of Medical Research, New Delhi.

Gupta, S.K.; Kalaiselvan, V.; Srivastava, S.; Saxena, R. and Agrawal, S.S. (2009). Inhibitory effect of Trigonella foenum-graecum on galactose induced cataracts in a rat model; in vitro and in vivo studies. J. ophthalmic Vis. Res., 4:213-219.

He, J.; Feng, Y.; Ouyang, H.Z.; Yu, B.; Chang, Y.X.; Pan, GX.; Dong, G.Y.; Wang, T. and Gao, X.M. (2013). A sensitive LC-MS/MS method for simultaneous determination of six flavonoids in rat plasma: Application to a pharmacokinetic study of total flavonoids from mulberry leaves. J. Pharm. Biomed. Anal., 84:189-195.

Indian Pharmacopoeia (2018). Volume III, Ministry of Health and Family Welfare, $8^{\text {th }}$ edition, Government of India.

Jiang, J.X.; Zhu, L.W.; Zhang, W.M. and Sun, R.C. (2007). Characterization of galactomannan gum from fenugreek (Trigonella foenum-graecum) seeds and its rheological properties. Int. J. Polym. Mater., 56:11451154.

Kagawad, P.; Gharge, S.; Jivaje, K.; Hiremath, S.I. and Suryawanshi, S.S. (2021). Quality control and standardization of quercetin in herbal medicines by spectroscopic and chromatographic techniques. Future J. Pharm. Sci., 7(1):1-12.

Khoja, K.K.; Shaf, G.; Hasan, T.N.; Syed, N.A.; Al-Khalifa,A.S.; Al-Assaf, A.H. and Alshatwi, A.A. (2011). Fenugreek, a naturally occurring edible spice, kills MCF-7 human breast cancer cells via an apoptotic pathway. Asian Pac. J. Cancer Prev., 12:3299-3304.

Kia, A.G.; Ganjloo, A. and Bimakr, M. (2018). A short extraction time of polysaccharides from fenugreek (Trigonella foencem graecum) seed using continuous ultrasound acoustic cavitation: Process optimization, characterization and biological activities, Food Bioproc Tech., 11:2204-2216

Kim, H.P.; Mani, I.; Iversen, L. and Ziboh, V.A. (1998). Effects of naturallyoccurring flavonoids and biflavonoids on epidermal cyclooxygenase and lipoxygenase from guinea-pigs. Prostaglandins Leukot. Essent. Fatty Acids, 58(1):17-24.

Kokate, C.K. (1994). Practical Pharmacognosy. $4^{\text {th }}$ ed., Vallabh Prakashan, Delhi, India, pp:20-27. 
Kokate, C.K.; Purohit, A.P. and Gokhale, S.B. (2005). "A Textbook of Pharmacognosy”. Nirali Prakashan, Pune. 20087.

Kose, L.P.; Gülcin, I.; Gören, A.C.; Namiesnik, J.; Martinez-Ayala, A.L. and Gorinstein, S. (2015). LC-MS/MS analysis, antioxidant and anticholinergic properties of galanga (Alpinia officinarum Hance) rhizomes. Ind. Crops Prod., 74:712-721.

Kurzawa, M. (2010). Determination of quercetin and rutin in selected herbs and pharmaceutical preparations. Anal. Let., 43(6):993-1002.

Malik, T.; Madan, V.K. and Prakash, R. (2020). Herbs that heal: Floristic boon to the natural healthcare system. Ann. Phytomed., 9(2):6-14.

Mathe, H.A. (2018). Remarks to the recent trends in exploring medicinal plant diversity. Ann. Phytomed., 7(2):1-5.

Mehrafarin, A.; Rezazadeh, S.H.; NaghdiBadi, H.; Noormohammadi, G.H.; and, E. and Qaderi, A. (2011). A review on biology, cultivation and biotechnology of fenugreek (Trigonella foenum graecum L.) as a valuable medicinal plant and multipurpose. J. Med. Plants, 10:6-24.

Montgomery, J. (2009). The potential of fenugreek (Trigonella foenum graecum) as a forage for dairy herds in central Alberta. University of Alberta, USA. pp:4-15.

Mostofa, R.; Ahmed, S.; Begum, M.M.; Rahman, M.S.; Begum, T.; Ahmed, S.U.; Tuhin, R.H.; Das, M.; Hossain, A.; Sharma, M. and Begum, R. (2017). Evaluation of anti-inflammatory and gastric antiulcer activity of Phyllanthus niruri L.(Euphorbiaceae) leaves in experimental rats. BMC Complement. Altern. Med., 17(1):1-10.

Naidu, M.M.; Shyamala, B.N.; Naik, J.P.; Sulochanamma, G. and Srinivas, P. (2011) Chemical composition and antioxidant activity of the husk and endosperm of fenugreek seeds. LWT-Food Sci. Technol., 44:451-456.

Nanusha, M.Y.; Krauss, M.; Schönsee, C.D.; Günthardt, B.F.; Bucheli, T.D. and Brack W. (2020). Target screening of plant secondary metabolites in river waters by liquid chromatography coupled to high-resolution mass spectrometry (LC-HRMS). Environ. Sci. Eur., 32(1):1-1.

Pandey, H. and Awasthi, P. (2015). Effect of processing techniques on nutritional composition and antioxidant activity of fenugreek (Trigonella foenum-graecum) seed flour. J. Food Sci. Technol., 52:1054-1060.
Parihar, B.S.; Chaudhary, P.; Mehra, R.K. and Ahmad, S. (2014). Herbal plants : A boon for ulcer disease. Int. J. pharm. Chem. Sci, 3:708-713.

Pathak, K. and Das, R.J. (2013). Herbal medicine: A rational approach in healthcare system. Int. J. Herb. Med., 1:86-89.

Rabi, T. and Bishayee, A. (2009). Terpenoids and breast cancer chemoprevention. Breast Cancer Res. Treat., 115(2):223-39.

Salah, N.; Miller, N.J.; Paganga, G.; Tijburg, L.; Bolwell, G.P. and Riceevans, C. (1995). Polyphenolic flavanols as scavengers of aqueous phase radicals and as chain-breaking antioxidants. Arch. Biochem. Biophys., 322(2):339-46.

Sambandam, B.; Thiyagarajan, D.; Ayyaswamy, A.; Raman, P.; Kulasekaran, J. and Venkatasamy, H. (2016). Extraction and isolation of flavonoid quercetin from the leaves of Trigonella foenum graecum and their antioxidant activity. Int. J. Pharm. Sci., 8(6):120-124.

Shah, B.N. and Seth, A.K. (2009). Text book of pharmacognosy and phytochemistry. Elsevier India.

Sulaiman, C.T. and Balachandran, I. (2016). LC/MS characterization of antioxidant flavonoids from Tragia involucrata L. Beni-Seuf Univ. J. Appl. Sci., 5(3):231-235.

Thakur, K.; Navdeep, A.; Jaswal, S. and Bhatt, A.K. (2018). Evaluation of antimicrobial potential of root extract of Asparagus racemosus Willd. and bark extract of Juglans regia L. against pathogenic bacterial isolates. Ann. Phytomed., 7(2):64-69.

Tiwari, B.K.; Abidi, A.B.; Rizvi, S.I. and Pandey, K.B. (2016). Phytochemical screening and evaluation of antioxidant potentials of some Indian medicinal plants and their composite extract. Ann. Phytomed., 5(1):99-103

Verma, S. and Singh, S.P. (2008). Current and future status of herbal medicines. Vet. World, 1:347-347.

Vinay Sharma (2021). Ayurveda and remedial plants in medication. Ann. Phytomed., 10(1):1-5

Wagner, K.H. and Elmadfa, I. (2003). Biological relevance of terpenoids. Ann. Nutr. Metab., 47(3-4):95-106.

Zargar, S. (2014). Protective effect of Trigonella foenum-graecum on thioacetamide induced hepatotoxicity in rats, Saudi J. Biol Sci., 21:139-145. 